\title{
A condição obscura: Reflexões sobre as políticas de imigração e controle de estrangeiros em Portugal
}

The Obscure Condition: Reflections on immigration policies and foreigner control in Portugal

La condition obscure : réflexions sur les politiques d'immigration et de contrôle d'étrangers au Portugal

Igor José de Renó Machado

\section{CpenEdition}

\section{Journals}

Édition électronique

URL : http://journals.openedition.org/rccs/4038

DOI : $10.4000 /$ rccs. 4038

ISSN : 2182-7435

Éditeur

Centro de Estudos Sociais da Universidade de Coimbra

Édition imprimée

Date de publication : 1 mars 2011

Pagination : 125-145

ISSN : 0254-1106

Référence électronique

Igor José de Renó Machado, « A condição obscura: Reflexões sobre as políticas de imigração e controle de estrangeiros em Portugal », Revista Crítica de Ciências Sociais [En ligne], 92 | 2011, mis en ligne le 01 novembre 2012, généré le 04 mai 2019. URL : http://journals.openedition.org/rccs/4038 ; DOl : $10.4000 /$ rccs. 4038

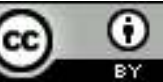




\section{A condição obscura: Reflexões sobre as políticas de imigração e controle de estrangeiros em Portugal}

O artigo propõe uma reflexão antropológica sobre as leis portuguesas de controle da imigração e concessão de nacionalidade. Ao mesmo tempo que procuram estabilizar um contingente de imigrantes numa condição vulnerável, as leis, como um todo, compartilham uma noção de aversão à diferença radical, procurando sempre aportuguesar os estrangeiros. Os diferentes mecanismos construídos para atingir esse objetivo são analisados em detalhe.

Palavras-chave: imigração, legislação portuguesa, Serviço de Estrangeiros e Fronteiras (SEF), controlo de estrangeiros, lei da nacionalidade, naturalização.

\section{Introdução}

Este artigo $^{1}$ reflete sobre um conjunto de leis que regulam a imigração em Portugal, país que passou, entre finais dos anos 1970 e 1980, por uma mudança significativa no seu perfil populacional. De país de emigração, passou a ser cada vez mais também um país de imigração, mesmo que convivendo continuamente com a saída de nacionais para o exterior. Essa mudança conduziu o Estado português a revisar as leis que regulam a entrada, saída e permanência de estrangeiros e também as leis que regulam a atribuição de nacionalidade. Na primeira parte do texto farei um breve historial dessas leis, que são muitas. Apenas nos últimos 10 anos, a "lei de entrada, saída e permanência” passou por duas mudanças legislativas, até ser substituída por outra, em 2007. Isso denuncia a importância da imigração como uma espécie de fato social total maussiano na sociedade portuguesa: muito converge para a imigração.

Este artigo propõe uma reflexão antropológica sobre o que está por trás da legislação, mais do que uma análise minuciosa do que está no texto das

\footnotetext{
${ }_{1}^{1}$ Agradeço aos pareceristas anônimos as valiosas sugestões e críticas.
} 
leis, daquilo que muda, das exigências que se movem, das questões que imperam em uma ou outra. Isso explica também porque não se considera o resultado da produção legislativa em relação às concepções mais formais que informariam a produção das leis (como a de cidadania). Esse último tipo de trabalho tem sido bem conduzido por intelectuais e juristas portugueses. ${ }^{2}$ A perspectiva antropológica adotada parte da idéia de que a legislação portuguesa sobre os estrangeiros implica em concepções portuguesas de diferença, mesmo que negociadas com concepções formais do mundo do direito. Isso explica também o caráter dirigido do resumo desse processo apresentado na primeira parte: interessa levantar algumas informações sobre a legislação, que vão servir de base à discussão apresentada na segunda parte do texto, que propõe uma reflexão sobre o que significa legislar sobre o estrangeiro. Assim, este texto pretende ser uma contribuição para uma antropologia da diferença em Portugal, assim como para uma antropologia do direito.

A segunda parte do artigo discute o caráter discricionário dessas leis, que promovem cortes entre grupos de pessoas que podem existir sob a rubrica de "legais" e daquelas que deveriam desaparecer sob a rubrica de "ilegais". Mas o fato é que elas não desaparecem e essa "insistência ontológica", digamos, costuma dificultar a vida dos legisladores e disparar processos críticos sobre o próprio caráter da sociedade portuguesa. Pretendo pensar sobre como as legislações implicaram em cortes ontológicos sucessivos, trazendo para uma condição de existência civil conjuntos sucessivos de ex- "ilegais"; como determinadas alteridades foram ou são sistematicamente mais aceitáveis que outras; como hierarquias de alteridades foram se consolidando, e a partir de que critérios; e como a última legislação - a de 2007 - implica numa ruptura abrupta numa tradição de reconhecimento tardio de "ilegais", em prol de uma política oficial de constituição do que podemos chamar de "condição obscura", onde os "ilegais" permanecerão sempre, com exceção daqueles momentos em que aparecem para serem expulsos.

É preciso fazer notar que as leis portuguesas aqui analisadas foram produzidas dentro de um quadro de orientações supra-nacionais, basicamente relativas à União Européia. Não é o escopo deste artigo entender a relação entre a produção legislativa portuguesa e esse quadro supra-nacional, mas vale sublinhar que as leis aqui analisadas de forma "nacional" e destacada são produto de um intenso debate intra-europeu. Seria interessante comparar a legislação portuguesa a outras para entender a influência de concepções

\footnotetext{
${ }^{2}$ A análise dos condicionantes jurídicos que subjazem à experiência dos imigrantes em Portugal tem sido ricamente analisada por diversos autores portugueses, como Costa (2006), Canotilho (2000), Moura Ramos (1996 e 2003), Torres (1993), Pereira da Silva (2004), Urbano de Sousa (2000, 2002), Jerónimo (2001), Riquito (2000), Fidalgo de Freitas (2009), entre outros.
} 
formais de cidadania, por exemplo, relativamente a outras legislações. ${ }^{3}$ Contudo, o objetivo do artigo é entender a idéia de "diferença" que se pode extrair do conjunto da legislação sobre a imigração em Portugal nos últimos 30 anos. Isso impõe também outra dificuldade: a discussão bibliográfica sobre "diferença" em Portugal raramente lida com as questões do direito, enquanto os especialistas do direito têm justas preocupações com aspectos formais da constituição das leis. Há aqui que se constituir um campo próprio de discussão, e o artifício foi acentuar a descrição empírica das leis e deduzir delas o que chamei de "espírito de assemelhamento". As duas partes finais do artigo analisam a legislação mais recente, que supostamente rompe com essa lógica, mas na verdade apenas a reafirma; e também as exceções aos princípios de legalização, demonstrando a operacionalização da lógica do assemelhamento.

\section{Políticas migratórias}

O ano de 1981 é identificado por Baganha e Góis como ano de viragem na imigração em Portugal, devido à criação do enquadramento jurídico. O DL (Decreto-Lei) 264-B/81 regulava as entradas, permanências e saídas de estrangeiros em território português e a Lei $\mathrm{n}^{\circ}$ 37/81 mudou as regras da nacionalidade. O DL 264-B/81 aproximou a legislação de Portugal daquelas dos países da Comunidade Econômica Européia (CEE), e a lei da nacionalidade trocou o jus soli pelo jus sanguinis, dificultando tanto a aquisição de nacionalidade por nascimento em território aos filhos de pais não nacionais, quanto a aquisição de nacionalidade por casamento (Baganha e Góis, 1998/99: 266).

Para estes autores as mudanças legislativas propiciaram uma guinada rumo a uma identidade étnica primordial baseada na consangüinidade. Esta posição evidencia uma concepção de etnicidade como algo, de certa forma, modelado pelas intenções do Estado. Por outro lado, temos aqui uma óbvia relação entre o modelo de identidade consangüínea (e seu inevitável caráter racial) e o desenvolvimento de identidades étnicas. Aproximando-se das políticas européias, essa guinada marcaria a viragem entre um Portugal metrópole de um império para um Portugal europeu. ${ }^{4}$ A reordenação se

\footnotetext{
${ }^{3}$ Para uma tentativa de comparação em outros termos, especificamente antropológicos, ver Machado (2010).

${ }^{4}$ Essa análise pode ser relativizada, pois considero que é o reordenamento da imigração em Portugal que repõe didaticamente a pedagogia do pensamento imperial, significando que as políticas de disciplinarização da imigração e da marcação consangüínea da diferença são apenas uma forma de continuar a metrópole do império - metrópole que, como no século XIX, era periférica ao sistema europeu. Feldman-Bianco (2001) e Caetano da Silva (2003) demonstram como a metáfora da consangüinidade é extremamente ambígua quando tratamos de ex-império e
} 
evidenciou pela "discriminação positiva" (Baganha, 2001) dada aos imigrantes dos PALOP no enquadramento dessas leis. A discriminação positiva foi anunciada no DL 244/98 de 8 de agosto, que legislava sobre a entrada, permanência, saída e expulsão de imigrantes em Portugal. Segundo esse decreto, no seu artigo 85, os imigrantes dos PALOP e os brasileiros teriam direito à autorização de residência permanente após seis anos de permanência legal em Portugal, enquanto os demais imigrantes somente poderiam requerer esse direito após dez anos de residência no país. Em 2001, foi publicado o DL 4/2001, de 10 de janeiro, que introduziu alterações no DL 224/98, principalmente no que se refere à autorização de permanência.

O DL 4/2001 criou uma nova figura legal, a da autorização de permanência (AP), que embora seja parecida no nome com a autorização de residência (AR), era completamente diferente em seu conteúdo e para a organização da vida dos imigrantes. Esta última dava ao requerente aprovado direitos civis completos (menos direito de voto), que eram extensíveis a sua família. A autorização de permanência concedia a maioria dos direitos, mas negava o direito à residência permanente, pois limitava a estadia do imigrante ao máximo de cinco anos. Esta lei previa a reunião familiar e exigia do imigrante um contrato de trabalho, concedido pelo empregador. Além disso, estipulava a necessidade da autorização do Instituto de Emprego e Formação Profissional, que anualmente elaboraria uma lista com previsão da mão-de-obra deficitária em categorias específicas. Apenas os trabalhadores estrangeiros que quisessem (e pudessem) exercer as profissões mencionadas no relatório poderiam pedir a autorização de permanência.

Até à divulgação da primeira lista, os trabalhadores em "situação ilegal" puderam tentar obter a autorização de permanência independentemente das profissões exercidas, se possuíssem contrato de trabalho, o que explica a corrida à legalização no ano de 2001. Ou seja, foi uma regularização extraordinária, dando visibilidade a quem se encontrava na "condição obscura" da "ilegalidade". Mas esses imigrantes ficaram submetidos ao condicionamento de um máximo de cinco anos de permanência. Para pedir a autorização de

\footnotetext{
ex-colônias. Assim, mudar o critério da nacionalidade não significa necessariamente uma virada anti-imperial, já que, longe disso, propicia a confusão simbólica que permite a proliferação de discursos ideológicos baseados nas metáforas de parentesco (Machado, 2009). Mais adiante, discutindo a nova legislação de imigração (2007), veremos mais sobre continuidades e descontinuidades em relação ao pensamento imperial.

5 A insistência no uso do termo "ilegal" se deve apenas à sua popularidade tanto na mídia escrita como no próprio texto das leis. Aparece, portanto, como um conceito nativo. Há autores que defendem a idéia de que o uso dessa palavra implica em produzir uma diferença estatutária que, de certa forma, legitima os atos de discriminação. Atento a essa crítica, acentuo que os "não-documentados", categoria que muitos preferem, são constantemente tratados como "ilegais" pelos mídia portugueses e pela própria legislação.
} 
residência definitiva o imigrante precisaria de estar em Portugal por seis anos consecutivos, no caso de membros da CPLP (Comunidade dos Países de Língua Portuguesa), e por 10 anos no caso dos demais (Machado, 2000).

No DL 4/2001, o artigo 85 foi mantido na forma anterior, o que significa que os falantes de português continuaram com um privilégio, embora menor. Menor porque entre as condições para que se pedisse a autorização de residência (AR) encontrava-se a necessidade de um visto de residência. Para obter a dispensa da apresentação do visto de residência para a requisição da AR, eram estabelecidas algumas condições. Com a figura da autorização de permanência (AP), uma nova possibilidade para a dispensa do visto igualou a chance dos imigrantes, qual seja, o fato de ter conseguido a AP por cinco anos consecutivos. Qualquer imigrante poderia requerer a AR provisória a partir desse período, mas os falantes de português ainda poderiam requerer a AR definitiva mais cedo que os demais imigrantes. A lei de 2001 evidenciava uma discriminação positiva para os imigrantes originários do antigo império colonial.

O DL 34/2003 (regulado posteriormente pelo DR - decreto regulamen$\operatorname{tar}-6 / 2004$ de 26 de abril), que veio a alterar o DL 224/98 e suas subseqüentes mudanças com o DL 4/2001, reescreveu o artigo 85, mas continuou a privilegiar imigrantes de países de língua oficial portuguesa. Assim, os migrantes de países dos PALOP e do Brasil poderiam agora requerer a AR após os cinco anos de estadia legal, mas os demais migrantes continuavam a ser discriminados: antes precisavam de 10 anos de permanência legal para requerer a AR definitiva, agora precisariam de oito, o que era uma melhora, mas ainda os deixava como cidadãos de $5^{\text {a }}$ classe. Quinta classe porque, como afirma Costa (2006: 14),

[...] não podemos afirmar a existência de um estatuto jurídico uniforme dos estrangeiros em Portugal, mas antes vários estatutos, cujo conteúdo é variável, em resultado do cruzamento das condições indicadas. Assistimos, pois, à institucionalização de estatutos jurídicos diferenciados, podendo ser indicadas as seguintes categorias principais de estrangeiros: cidadãos comunitários; cidadãos brasileiros; cidadãos lusófonos; outros.

Se considerarmos que o português nato é o cidadão de $1^{a}$ classe, teríamos os imigrantes de países onde a língua oficial não é o português (com exceção dos "estrangeiros" da Comunidade Européia, que nunca são considerados imigrantes) num quinto lugar na fila de graus de cidadania. A especificidade do brasileiro nesta lista, segundo Costa, deve-se à existência de tratados específicos entre o Brasil e Portugal, que beneficiam estes migrantes em relação aos demais. 
Estes países assinaram um "Estatuto de Igualdade de Direitos e Deveres", regulamentado em Portugal através do decreto-lei 154/2003, que "visa concretizar o regime processual de atribuição e registro do estatuto de igualdade aos cidadãos brasileiros residentes em Portugal". ${ }^{6}$ Destaca-se nesse decreto - decorrente do "Tratado de amizade, cooperação e consulta entre a República Federativa do Brasil e a República Portuguesa”, assinado em 22 de abril de 2000, em Porto Seguro - o seguinte trecho do artigo 16:

ao cidadão brasileiro investido no estatuto de igualdade é reconhecido, nos termos da lei e em condições de reciprocidade, direitos não conferidos a estrangeiros, salvo o acesso aos cargos de Presidente da República, Presidente da Assembléia da República, Primeiro-Ministro e presidente dos tribunais supremos e o serviço nas Forças Armadas e na carreira diplomática.

Aqui vemos, de antemão, a condição especial de imigrantes brasileiros em Portugal (e de portugueses no Brasil), que estão oficialmente cobertos pela assinatura desse tratado, que substituiu a anterior "Convenção sobre Igualdade de Direitos e Deveres entre Brasileiros e Portugueses", celebrada em Brasília, no dia 7 de setembro de 1971. Percebemos que o tipo de relação entre os Estados-Nação dos quais partem emigrantes e aqueles que os acolhem é fundamental na conduta do Estado-receptor em relação a essas pessoas. No caso de Brasil e Portugal, é evidente que a densa história entre os dois países é motivo de cuidados especiais com os brasileiros em Portugal, bem como o contrário. Esse tipo de relação histórica e sistemática tem conseqüências determinantes na construção de hierarquias de alteridades nos países que produziram essas relações.

É o caso do Estado português, que, devido à sua intensa relação com o Brasil, não pode deixar de ouvir os apelos deste em relação aos seus nacionais em situação ilegal em território lusitano. Há, assim, certa correspondência entre a densidade da história e a construção das hierarquias de alteridade. Neste sentido, os imigrantes brasileiros diferem dos demais imigrantes, pois têm sobre si a influência de um Estado que pode fazer demandas que não são facilmente deixadas ao vento. Porém, este é um aspecto que depende das configurações políticas, pois se o reconhecimento da especificidade dos brasileiros é real, a aplicação dessas vantagens comparativas é relativa. Por outro lado, comparando-se o anterior e o atual tratado de amizade entre Portugal e o Brasil, os respectivos nacionais perderam direitos. O tratado anterior garantia o reconhecimento dos direitos à equivalência dos diplomas

\footnotetext{
${ }^{6}$ Jornal O Sabiá, edição de julho de 2003.
} 
entre os dois estados, mas não especificava como isso deveria ser feito. Assim, as lutas de profissionais brasileiros por reconhecimento de diplomas tinham um forte respaldo legal. O novo tratado reafirmou o direito de reconhecimento de diplomas, contanto que esse processo fosse realizado pelas universidades e pelas associações profissionais, quando fosse o caso. Num mercado extremamente competitivo, imagina-se que as associações não são muito flexíveis em relação a esta concessão de reconhecimento. ${ }^{7}$

Em 11 de julho de 2003, foi assinado o "acordo Lula", um protocolo entre os Estados brasileiro e português que previa a legalização de imigrantes brasileiros por meio de um processo extraordinário dirigido especialmente aos brasileiros. O acordo previa a legalização dos brasileiros que tivessem um contrato de trabalho e houvessem chegado antes de julho de 2003. Segundo Padilla (2005: 7), cerca de 30000 brasileiros se inscreveram neste processo, o que significa que além dos números oficiais, que davam conta de mais ou menos 65000 brasileiros em Portugal, era preciso contar que existiam pelo menos mais 30000 brasileiros não documentados (invisibilizados na condição obscura). A aplicação desse acordo foi complicada, tendo sido objeto de intensas disputas entre a CBL (Casa do Brasil de Lisboa) e o governo português. Em dezembro de 2003, o jornal da CBL, o Sabiá (ed. 59), trazia uma reportagem sobre "a lentidão e os obstáculos que (vinham) acompanhando a execução” do acordo luso-brasileiro. A reportagem afirma:

Acordo luso-brasileiro: Vistos a passo de caracol: dos 30 mil brasileiros que se inscreveram para obter o visto de trabalho, somente três mil conseguiram prorrogação do visto de turista enquanto aguardam o processo. Outro problema tem sido a posição das empresas: com medo de serem multadas estão a demitir funcionários (embora pelo acordo nenhuma contratação feita até 11 de julho seja considerada ilegal).

Em abril de 2004, apenas 1687 imigrantes haviam conseguido a legalização. ${ }^{8}$ Até 31 de março de 2005, 16173 vistos foram emitidos, ${ }^{9}$ ou seja, cerca da metade dos imigrantes brasileiros que entraram com o pedido ainda não tinham obtido resposta, mais de um ano depois.

Posteriormente, o acordo foi estendido aos demais imigrantes em Portugal, pois ficou evidente que o governo não poderia privilegiar tanto apenas uma população específica. Neste sentido, um novo processo de legalização extraordinária teve lugar em 2004, sob os auspícios do decreto regulamentar

\footnotetext{
7 Sobre esse assunto, ver Machado 2009, que analisa em detalhe o caso dos dentistas, detonador, de certa maneira, das mudanças nos tratados.

8 Sabiá 62, abril de 2004.

9 Conferir Costa, 2006: 6.
} 
n. ${ }^{\circ}$ 6/2004, de 26 de abril, que veio regular novamente a entrada, saída, permanência e afastamento de estrangeiros em Portugal, alterados no DL 34/2003. Se o processo foi estendido aos demais imigrantes, isso não significou o fim das vantagens explícitas a alguns dos grupos imigrantes. Os brasileiros, especificamente, foram duplamente beneficiados, uma vez que poderiam se candidatar também a este novo processo.

Esta revisão da legislação continuou a ser explicitamente lusófona, no caminho de privilegiar as diferenças que "fazem sentido" de um ponto de vista português. Logo em sua introdução, estabelece:

Desde logo, prevê-se uma importante inovação ao referir-se que na apreciação de alguns tipos de vistos o conhecimento da língua portuguesa deve ser tido em conta, podendo, nos casos de contingentação do número de vistos, constituir factor preferencial. Esta introdução do conhecimento do português como factor de preferência na concessão de vistos pretende reforçar as relações com os nacionais dos Estados culturalmente mais próximos de Portugal, como é o caso manifesto daqueles que fazem parte da Comunidade de Países de Língua Oficial Portuguesa, e também dos imigrantes de outros países que já tenham tido contacto com a língua e a cultura portuguesas.

Esse processo de legalização estendido também contou com as mesmas dificuldades enfrentadas pelos brasileiros no Acordo Lula, deixando milhares de imigrantes de fora (a estimativa do Jornal Sabiá era a de que, dos 53 mil inscritos, somente 15 mil conseguiriam regularizar sua situação). ${ }^{10}$ Vemos pela passagem acima que mesmo a resposta do governo português às demais populações imigrantes, que pressionaram contra a exclusividade dada aos imigrantes brasileiros, foi enviesada por um desejo de controle sistemático da diferença: uma verdadeira "gestão da diferença", de maneira a reforçar, mesmo com a grande quantidade, naquele momento, de imigrantes "de leste”, as hierarquias pós-coloniais (que poderíamos chamar pós-mas-ainda-coloniais).

A lei $\mathrm{n}^{\circ}$ 23/2007, de 4 de julho, que substituiu o DL 224/98 (e sucessivas alterações), alterou este estado de coisas: não há mais privilégios específicos aos "lusófonos" em termos de tempo para aquisição de estatutos mais permanentes de residência. Esta lei criou três estatutos de residência para imigrantes: a residência temporária, a permanente e a de longa duração, num caminho que parte da mais instável (temporária) para a mais estável (longa duração). A residência permanente é conseguida após cinco anos de

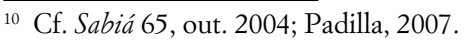


residência temporária, independentemente da nacionalidade do imigrante. Mas isso não significa que um certo "espírito de assemelhamento" não continue sento importante: um dos critérios para aceder à residência permanente é o conhecimento de português básico, enquanto para aceder à residência de longa duração é necessário conhecimento fluente de português básico.

Entenderemos o valor desse espírito de assemelhamento na exigência técnica de aprendizado de português (também regulado por portarias específicas) se compararmos as diferentes condições para solicitar residência permanente e residência de longa duração: as duas exigem cinco anos anteriores de estadia em Portugal em situação legal e meios de subsistência. A diferença é que a residência permanente exige que não se tenha sido condenado a mais de um ano de prisão, enquanto a de longa duração exige seguro de saúde. Tirando essa diferença econômica e outra de "segurança", o conhecimento da língua dá acesso, na verdade, a um estatuto mais estável.

\section{Assemelhamento como projeto}

Vimos que, até 2004, havia uma clara tendência, por parte dos legisladores portugueses, de proceder a um reconhecimento a posteriori daquelas pessoas que se encontravam dentro do país numa situação tida como "ilegal”. Essas eram pessoas de carne e osso, é sempre bom lembrar, que o Estado simplesmente desconsiderava por uma medida legal. Podemos entender essas leis não só como mecanismos de visibilização dos "ilegais", mas também como formas contínuas de manter invisíveis e "ilegais" determinados grupos de pessoas. Isso porque há sempre uma data de corte, após a qual se considera que ninguém será "ilegal", ou porque todos se legalizaram, ou porque as forças policiais impedirão de entrar ou expulsarão os "ilegais". Mas o fato é que nem todos se legalizam nos processos, nem os processos em si estancam a migração "ilegal".

A legislação de 2007, ao se recusar a fazer uma "regularização extraordinária" aparece, nesse contexto, menos como uma mudança no padrão anterior, e mais como uma radicalização do princípio legislativo que tem predominado: manter “ilegais" como "ilegais", não reconhecê-los a não ser em situações especiais. As leis anteriores eram mecanismos que separavam legais de "ilegais", deixando sempre alguns na "condição obscura", uma espécie de limbo gradual, cuja existência era pouco a pouco reconhecida. A atual legislação é uma tentativa de estabilizar a penumbra, pois claramente é um mecanismo que visa impedir o reconhecimento daquelas pessoas que permanecem na "condição obscura".

A análise da legislação deixou muito claro que o caminho da visibilização era articulado por uma concepção portuguesa de alteridade profundamente 
colonial..$^{11} \mathrm{O}$ privilégio de existência era mais facilmente concedido aos sujeitos que se adequassem às hierarquias coloniais. Já demonstrei em outro contexto (Machado, 2004) como essas hierarquias foram construídas, e aqui basta destacar o texto de Costa (2006), que deduz, a partir da legislação, a mesma hierarquia de alteridades. Os brasileiros têm um privilégio evidente: foram objeto de legislação exclusiva, contam com um acordo bilateral de concessão de direitos, etc. Seguem-se os "lusófonos" do ex-império e, depois, os "demais", aqueles que não têm relação com o império.

Podemos concluir que as leis montavam-se contra um pano de fundo óbvio: uma identidade portuguesa, pensada numa linha claramente colonial. A nova legislação talvez indique mudanças muito evidentes no que se chama de "identidade portuguesa", ao descolar-se, de alguma forma, de uma perspectiva colonial, não para apagá-la, mas apenas para ampliá-la de forma a subordinar as diferenças mais diferentes (aquelas que não se relacionam com o ex-império) à mesma lógica de assemelhamento.

A nova lei não privilegia os lusófonos "ontológicos", ou seja, aqueles que nasceram em países onde a língua oficial é o português. Nas legislações anteriores, esses sujeitos sempre podiam buscar um tipo de regularização mais definitiva antes dos demais imigrantes. Agora todos têm os mesmos direitos à legalização mais estável, contanto que saibam português. A condição para requerer uma legalização mais estável (na nova lei é chamada de "permanente" e de "longa duração") é o conhecimento da língua. Isso seria uma forma de assemelhamento pela praxis, em contraposição à ontológica (em que determinadas nacionalidades eram privilegiadas). $\mathrm{O}$ assemelhamento que se imagina é o proporcionado por um estado ao qual se pode chegar por vontade e força de espírito. Há até portarias legislando sobre o aprendizado de português e sobre a forma de avaliação que se espera.

Nesta lei, se estabeleceu um gradiente de tipos de legalização, daquela mais instável e reversível até à mais estável e menos reversível. Para além dessas autorizações de residência, há a possibilidade de naturalização, ${ }^{12}$ estatuto mais seguro e irreversível (a não ser por vontade própria do estrangeiro). Essas gradações modelam uma condição específica, que controla a visibilidade dos imigrantes em solo português: desde os que estão na penumbra e não são oficialmente vistos (os "ilegais") até os mais visíveis, aqueles

\footnotetext{
${ }^{11}$ Não se quer dizer que toda legislação que pensa no assemelhamento seja colonial, mas que a portuguesa, por conta de sua experiência colonial, reflete essa herança. Outras legislações, como a brasileira atual, por exemplo, são marcadas não pelo assemelhamento, mas pela desconfiança sistemática em relação ao imigrante, fato que é uma herança da legislação produzida durante o regime militar (1964-1980).

${ }_{12}$ Regida por outra lei, que comentarei adiante.
} 
naturalizados. Assim, a melhor imagem para retratar essa situação é a de um buraco: a planície representa a nacionalidade portuguesa e os degraus no buraco os níveis de visibilidade: quanto mais no fundo, mais invisível. As legislações fazem cortes arbitrários entre os mais e menos visíveis.

Vemos que há, portanto, uma radicalização de um princípio, ao invés de uma mudança geral de perspectivas. Diante de uma grande massa de "ilegais" que pretendem alcançar estatutos mais estáveis de permanência (aqueles que são difíceis de reverter), a escolha do Estado é um assemelhamento espiritual: apenas aqueles que se aportuguesam são mais aceitáveis. É o espírito colonial avançando para além da própria história colonial: é como se a conquista continuasse agora ao nível da identidade. ${ }^{13}$ Poderíamos dizer que essas leis são leis de assemelhamento, baseadas numa recusa constante de alteridades não domesticáveis. ${ }^{14} \mathrm{~A}$ escolha das hierarquias é claramente uma escolha de semelhança, dando mais facilidades e visibilidade a quem não é tão diferente. A possibilidade de abrir mão das hierarquias coloniais na estruturação da nova legislação é, por contraditório que pareça, uma radicalização desse espírito colonial, profundamente avesso à diferença. Isso porque a aversão à diferença se expressa no desejo de uma aportuguesização espiritual, expressa tecnicamente na necessidade do domínio do idioma para galgar níveis mais estáveis de legalização.

Uma vez visto o princípio geral das leis, passo a olhar para três detalhes que merecem ser notados no que tange a um entendimento antropológico dessas peças de construção de portuguesidade. Tratarei do tipo de exceção que pode trazer um imigrante à tona, ou seja, que pode tirá-lo da condição obscura; de como mesmo no interior da obscuridão o Estado não pode se furtar completamente a reconhecer essas pessoas; e do caráter instável do estatuto dos imigrantes que puderam se legalizar, uma vez que são constantemente ameaçados de perder seu lugar e serem novamente jogados naquela condição perversa.

\section{Des-legalizações}

Nesta seção me concentrarei na última lei, entendida como a radicalização do espírito das anteriores, pelos motivos acima explicitados. Passarei mais rapidamente pelas demais leis.

Vejamos o que permite a exclusão do estatuto de "legal”. Nas leis de 2001 e 2003, os estatutos temporários de permanência eram suspensos quando se

\footnotetext{
13 Trato por "espírito colonial de assemelhamento" as tendências luso-tropicalistas articuladas no Governo Colonial em seus extertores, como indicam Castelo (1998) e Alexandre (2000).

${ }^{14}$ Obviamente, esse é um fenômeno que perpassa a maioria, senão a totalidade, das legislações européias sobre imigração, não é uma exclusividade portuguesa.
} 
encerrava o prazo de validade se o solicitante não possuísse naquele momento um contrato de trabalho. Se o imigrante tivesse visibilidade (se ele emergisse do fundo da condição obscura) com acesso à autorização de residência temporária, ele dependia de um contrato de trabalho. Assim, se no período de renovação de sua licença temporária de residência o imigrante não apresentasse um contrato de trabalho, ele poderia voltar à obscuridade. De forma simples, não poderia mais continuar legalmente em Portugal. Para esse imigrante, cujo estatuto era menos estável, a aventura da imigração era ameaçada sempre por uma linha móvel: num momento ele era visível, no outro poderia não ser.

Ele dependia de uma condição para continuar visível, que ainda não era a de um assemelhamento pela práxis. Era apenas e tão somente uma condição de classe: sem ser trabalhador não poderia ser visível. Isso, obviamente, tinha implicações de ordem prática, especialmente no que diz respeito à vulnerabilidade dessa população frente ao capital. Ora, se a condição de visível dependia de o patrão manter o contrato de trabalho, é fácil imaginar o quão explorável era esse imigrante. O imigrante com estatuto instável, enquanto trabalhador, era um trabalhador dócil e muito subordinado. Isso indica um mecanismo cruel do capitalismo nessas sociedades européias, qual seja, a produção de trabalhadores ultra-dóceis. As conseqüências desse processo foram assunto de outro texto que produzi (Machado, 2005), no qual identifico esses imigrantes como "coisas", produtores de mais-valia radical. Eram ultra-explorados pelos patrões quando "ilegais", são explorados quando legais mas instáveis, são explorados pelo Estado, através das multas, das contribuições tributárias não retornáveis, e pelo Estado de origem, apenas interessado nas remessas.

$\mathrm{Na}$ legislação recente, há outras formas de perder o "estatuto visível", mesmo o mais estável. São elas: ausentar-se demais de Portugal, cometer crimes que resultem em mais de um ano de cadeia, serem considerados ameaças à segurança pública. Ao contrário das leis anteriores, a renovação do estatuto temporário não exige a apresentação de documentos já apresentados, facilitando a vida do imigrante. Nos textos das leis anteriores a condição ontológica de lusófonos era recortada por uma condição de classe exclusiva, ou seja, interessava o ser lusófono apenas na categoria explícita de trabalhador, uma forma de manter o estatuto de subalternidade atribuído aos lusófonos nas hierarquias coloniais. A radicalização em direção ao "espírito aportuguesado", ao assemelhamento pela práxis, por sua vez, deixa em segundo plano a condição de trabalhador para o acesso aos estatutos de visibilidade: o contrato é exigido apenas no primeiro pedido e há visto previsto para exercer atividade independente. Emerge, em substituição da questão do trabalho, a questão fiscal: a renovação dos estatutos menos estáveis depende de uma contribuição regular à segurança social. 
A questão da ausência, em termos de uma análise antropológica, é de grande importância. A lei de 2007 em seu artigo 85, diz:

2 - Sem prejuízo da aplicação de disposições especiais, a autorização de residência pode igualmente ser cancelada quando o interessado, sem razões atendíveis, se ausente do país:

a) Sendo titular de autorização de residência temporária, seis meses consecutivos ou oito meses interpolados, no período total de validade da autorização,

b) Sendo titular de uma autorização de residência permanente, 24 meses seguidos, ou, num período de três anos, 30 meses interpolados.

No caso do estatuto de residente de longa duração, a ausência de território da União Européia por doze meses seguidos, ou do território português por seis anos seguidos, conduz à perda do estatuto.

Por que razão a ausência injustificada produz a perda da estabilidade? Digamos, a princípio, que tornar-se invisível pela ausência conduz de volta àquela invisibilidade estrutural do imigrante "ilegal". Mas poderíamos avançar explicações menos simplistas. Vimos que os estatutos de visibilidade vão ficando mais estáveis à medida que os sujeitos se aportuguesam e, portanto, tornam-se menos diferentes, num contexto de aversão à diferença. O índice usado na estruturação da legislação para medir a aportuguesização é o tempo e a disposição de aprender a língua. Assim, o tempo presente no território é um fator de aportuguesização. ${ }^{15}$ Não apenas por conta do tempo em si, mas o que ele representa em termos de um índice "oculto" de aportuguesização, a co-substancialidade. Convivência mútua pode significar o compartilhamento de substâncias, e vários autores indicam como, no nível do convívio dos lares, a substância pode produzir assemelhamento (ver Carsten, 2004). Também muito se escreveu sobre como as nações estão, de alguma forma, se apresentando como metáforas da família (idem), principalmente naquilo que estabelece linhas de filiação e pertencimento.

Ora, aqui o tempo produz co-substancialidade entre imigrantes e nativos, articulando um assemelhamento pela práxis. Esse assemelhamento pode ruir lentamente com a ausência prolongada. Obviamente, à medida em que os estatutos indicariam estados mais avançados de aportuguesização, quanto mais estável mais tempo levaria para perder a substância acumulada no convívio. O espírito português é a substância que se adquire com a convivência em Portugal. A ausência indica uma reversão no processo e também uma

15 “Aportuguesar", na acepção que utilizo aqui, é assemelhar pela "língua e costumes", num espírito colonial (não seria difícil estabelecer relações com o famoso estatuto do indigenato de 1961). 
diferenciação ontológica entre portugueses e aportuguesados (os imigrantes com seus vários graus de estabilidade legal): um português nato nunca perde sua nacionalidade, já um imigrante com estatuto de residente de longa duração pode perdê-la. O português nato é ontologicamente português, não corre o risco de desubstancialização; o imigrante residente (em graus de legalidade distintos) sempre precisa constituir a portuguesidade com a substância compartilhada, que pode ser perdida. Essa diferenciação é expressa na legislação de forma muito clara.

O caso de outra legislação, a lei da nacionalidade, serve como contraponto para a reflexão acima. Sendo originária de 1981 (Lei n ${ }^{\circ} 37 / 81$ ), passou até aqui por quatro alterações, sendo a última de 17 de abril de 2006. Esta lei regula quem tem direito à nacionalidade portuguesa. Os estrangeiros que conseguem a naturalização passam a ser "ontologicamente" portugueses e não podem perder a nacionalidade, a não ser por vontade própria. Ou seja, entre uma residência de longa duração e a naturalização há uma diferença de qualidade e não de grau.

Essa legislação de nacionalidade é amplamente condicionada por índices de substância/tempo: ela concede nacionalidade àqueles nascidos de ao menos um pai estrangeiro, caso este tenha nascido em Portugal, independentemente do seu título ou situação legal. A lei de nacionalidade garante que aqueles "ilegais" não se perpetuem enquanto gerações: o neto de um "ilegal" hoje será necessariamente português, se todos se mantiverem em Portugal. Também garante a nacionalidade àquele que tiver nascido de pais imigrantes com estatuto legal por 5 anos e todos os que tenham nascido em Portugal e não tenham outra nacionalidade. Um filho de estrangeiro nascido em Portugal cujo pai esteja há dez anos morando no país também pode aceder à naturalização. Pode igualmente solicitar a naturalização o filho de imigrante que tenha nascido em Portugal e aí tenha concluído o $1^{\circ}$ ciclo do ensino básico. Essas regras de concessão de nacionalidade são substantivas, pois pressupõem que, dado o tempo suficiente, é possível uma passagem para um estatuto definitivo de nacionalidade. A partir desse ponto, não é preciso mais construir a portuguesidade, pois não se pode mais perdê-la: está-se tão cheio de substâncias compartilhadas que não se corre mais o risco de "esvaziar".

Outro critério da lei que garante uma naturalização por co-substancialidade é o casamento ou união de fato com nativos do país. Se o imigrante se mantiver casado por três anos, pode aceder à nacionalidade. O compartilhamento substantivo, no caso, é óbvio. Não é por menos que a legislação de migração, pela primeira vez, penaliza os falsos casamentos, aqueles onde não há co-substancialidade: o artigo 186 atribui pena de dois a cinco anos de prisão para os sujeitos de falsos casamentos. Mas o que indica de fato e 
explicitamente o índice da substância nas considerações sobre o assemelhamento do estrangeiro ao nacional é a alínea a) do artigo 9 da lei de nacionalidade, que trata de explicitar aquilo que pode impedir o Estado de conceder a nacionalidade: "a inexistência de ligação efectiva à comunidade nacional". A explicação em termos de substância como índice oculto de aportuguesização deriva mais explicitamente de considerações que farei a seguir sobre formas especiais de ganhar a visibilidade e não das que permitem a sua perda.

Tudo isso para explicar o valor da "ausência" do imigrante legalizado, como prova para os legisladores de não co-substancialidade. Os outros casos de possibilidade de perda dos estatutos menos estáveis de visibilidade se dão por cometer crimes que resultem em condenação de mais de um ano de prisão e por ameaças à segurança pública. Os dois casos indicariam índices definitivos de não-comunhão com a nação e com o espírito português, sendo possível uma regressão para a condição obscura do imigrante em Portugal (no caso apenas depois de um regresso clandestino pós-expulsão).

\section{Exceções ontológicas}

A nova legislação aplica algumas exceções aos princípios de legalização. Algumas situações permitem que estrangeiros possam solicitar a regularização de sua situação mesmo sem preencher as condições fundamentais, no caso principalmente a posse de um visto de permanência emitido antes de entrar no país. Há condições especiais que permitem uma flexibilização, e considerá-las com atenção pode ajudar a entender os mecanismos de visibilização e invisibilização.

Dentre as situações excepcionais, que permitem a legalização sem o visto, vale destacar as seguintes:

1) Crianças que tenham nascido em Portugal, aí permanecendo ilegalmente e que estejam freqüentando a educação pré-escolar, o ensino básico, o ensino secundário ou profissional, bem como aos progenitores que sobre elas exerçam o poder paternal efetivo;

2) Estrangeiros, filhos de imigrantes legais, que tenham atingido a maioridade e permanecido em Portugal desde os dez anos de idade;

Essas duas exceções indicam o valor da co-substancialidade na condução das políticas de migração. Crianças que tenham nascido em Portugal de pais na "ilegalidade" são sujeitos de cuidado especial: se estudam, podem ser legalizadas e, por extensão, podem dar aos pais o direito de se visibilizarem. A explicação para essa exceção - muito louvável - é aquela da substância que aventamos anteriormente, ou seja, dado que essas crianças são evidentemente co-substantivas com os portugueses, fato que a escolarização comprova (na perspectiva de que a escola cria portugueses), a elas 
deve ser reconhecida a portuguesidade. E assim o fazendo, é preciso retirar também do limbo aqueles que são os responsáveis por elas.

O caso de crianças que não freqüentam a escola, nascidas em Portugal de pais "ilegais", não é abarcado por essa regra, indicando que esta seria uma forma de os pais manterem os filhos como diferentes. A escola assume assim papel fundamental na constituição de novos portugueses, explicando também por que qualquer imigrante ilegal pode colocar seus filhos na escola (o que discutirei rapidamente a seguir). O caso daqueles imigrantes que atingem a maioridade em Portugal e estejam no país desde os 10 anos de idade segue a mesma lógica da co-substancialização: passar a infância e adolescência em Portugal é o suficiente para conseguir a legalização, independentemente da escola. Pressupõe-se, portanto, que durante a formação da pessoa, em tenra idade, a presença em Portugal por longo tempo é suficiente para produzir o assemelhamento necessário.

Outras duas situações são passíveis de legalização sem visto:

A situação dos que têm filhos residentes (legalmente) ou com nacionalidade portuguesa;

Os maiores que nasceram em Portugal, que não tenham se ausentado do país, e lá tenham permanecido desde antes dos 10 anos.

O segundo caso traduz o quanto a escola, como máquina de aportuguesização, é importante: caso o filho de imigrante nascido em Portugal não tenha passado pela escola, poderá se legalizar apenas a partir da maioridade, com a condição de não-ausência desde antes dos 10 anos. Já discuti acima o valor simbólico da ausência para as políticas de assemelhamento, e aqui fica evidente mais uma vez essa relação. O primeiro caso traduz outra ligação de co-substancialidade: se o imigrante misturou substâncias com um nacional e produziu um filho português, pode ser tirado da condição obscura. Pode ser visibilizado.

Outro caso interessante de exceção à regra do visto é o do imigrante que cumpriu serviço militar efetivo nas Forças Armadas Portuguesas: neste caso ele pode requerer a legalização sem o visto. Isso também sinaliza uma co-substancialidade com a nação portuguesa, sendo o exército uma máquina de produção de portuguesidade similar à escola, só que mais efetiva; capaz de aportuguesar indivíduos menos jovens e em menos tempo (artigo 122, alínea h). ${ }^{16}$

\footnotetext{
${ }^{16}$ Não está claro como um estrangeiro pode servir o exército português. Essa regra deve se referir, ainda, aos retornados das guerras coloniais que não possuíam o estatuto de portugueses. A lei 174/99 de 21 de setembro, que trata do serviço militar, especifica no artigo 1, alínea 2, que "O serviço militar integra-se no contributo para a defesa nacional, no âmbito militar, a prestar pelos cidadãos portugueses, nos termos da presente lei." Portanto, seria impossível um estrangeiro não documentado adentrar o serviço militar.
} 
Há uma exceção que merece ser destacada: é a concedida àqueles que tenham tido algum direito de residência caducado, mas que se mantiveram em território português. Essa lei dá uma indicação interessante, que é a possibilidade de revisibilizar aquele imigrante que foi tirado da condição obscura, mas que, devido ao seu estatuto instável, acabou voltando à escuridão. A lei deixa claro que aqueles que já foram "vistos" pelo Estado têm a chance de o serem novamente. Interessante notar que a lei não concede direitos de possibilidade de legalização àquele que entrou ou permaneceu ilegalmente em Portugal depois da maioridade e nunca tenha se legalizado em nenhum dos processos de legalização anterior. Isso é o que chamo de "estabilização da condição obscura", determinando a invisibilidade sistemática daqueles que são considerados menos assemelháveis, justamente por terem chegado mais velhos e por não terem estudado em escolas portuguesas. Para esses parece que o tempo não é suficiente para constituir um assemelhamento eficiente.

Todas essas exceções indicam a operacionalização da lógica da co-substancialidade: há formas e formas de obter uma comunhão de substância ou se aproximar dela. O tempo em si é uma forma, mas muito menos eficiente. Ele é mais importante quando significa ausência, ou seja, como índice que rompe um processo de co-substancialização. Outra forma é passar por instituições que conduziriam a uma aportuguesização compulsória: a escola e as forças armadas. Uma terceira maneira é a mistura de substância com os nativos: quando é definitiva a mistura, produzindo pequenos portugueses, o direito à ausência do visto para solicitar a legalização é imediata. No caso do casamento com uma mistura menos "definitiva" (quando não há filhos), são necessários três anos para pedir, não a legalização (a lei de imigração de 2007 não menciona o casamento em qualquer lugar), mas a naturalização. O fato de o casamento não constar na lei de migração é claramente uma forma de combater os casamentos por conveniência, já que a burocracia para movimentar um processo de naturalização é muito maior do que a de um processo de legalização. Assim, a comunhão de substância pelo casamento seria legitimada, em última instância, apenas pela conclusão de um processo muito mais denso e demorado.

Passemos à última parte, aquela que trata de como mesmo no interior da condição obscura o Estado não pode se furtar a dar alguma visibilidade aos imigrantes "ilegais". 


\section{O limbo, os direitos e as políticas de estabilização da invisibilidade}

Como fim da reflexão sobre as leis de migração, vale destacar a forma elíptica como os "ilegais" são mencionados enquanto portadores de direitos na lei de 2007 e anteriores, já que em geral a concessão de direitos aparece indiretamente. Lendo as exceções às regras de exigência de visto para solicitar a legalização (cf. supra), percebemos que o imigrante ilegal pode colocar seu filho na escola. A lei feita como uma forma de estabilização de invisibilidade só dá visibilidade ao "ilegal" quando trata de sua expulsão ou de definir quando algum estrangeiro é considerado "ilegal".

Temos uma coerência com a lógica de assemelhamento que rege essa legislação, constituída como uma forma de construção de "aportuguesados". Essa é também uma forma de rejeição das "diferenças diferentes", aquelas que fogem a um quadro de sentido colonial. Por outro lado, outras legislações tratam explicitamente dos imigrantes "ilegais", chamados de "estrangeiros em situação irregular", tratando de conceder-lhes direitos. São as que garantem o acesso de imigrantes na condição obscura à escola e à saúde. Garantir o acesso à escola, como vimos acima, é uma forma de construir o espírito português, ou seja, de assemelhar. Garantir o acesso à saúde é um direito fundamental cuja negação pode levar à ameaça da saúde pública.

Mesmo no limbo da "irregularidade", o Estado interessado em estabilizar a condição obscura reconhece direitos que são como luzes fugidias lançadas à escuridão. Essas luzes têm intenções de assemelhar, pois a escola é lugar precioso das políticas de assemelhamento. O interessante dessa visibilidade na obscuridão é o DL 67/2004, que cria um registro nacional de menores estrangeiros em situação irregular, com o fim específico de auxiliar no acesso desses jovens à escola e à saúde. Esse registro não pode ser usado como prova contra o imigrante por nenhum órgão português. Do ponto de vista da argumentação que venho elaborando, interessa refletir sobre as razões por que não há um registro similar para migrantes maiores em situação irregular. É possível afirmar que há um decreto como este apenas para os menores porque eles são considerados como "assemelháveis", como vimos acima, enquanto os adultos não. Assim, é preciso dar visibilidade legal a esses "assemelháveis", a fim de que facilmente tenham acesso à escola e à saúde. Para os adultos, se mantém a perspectiva elíptica: podem ter acesso à saúde, mas não se fará uma lista nacional "blindada" para garantir seus direitos. Esses devem continuar na invisibilidade, mesmo quando acedem a direitos básicos, sempre elipticamente.

Vimos ao longo do texto como as leis sobre imigração em Portugal seguem um caminho que se opõe à diferença, dando margem à visibilidade dos 
sujeitos em "situação irregular" apenas na medida em que se assemelhem. Aos que permanecem renitentemente diferentes, as políticas constroem uma estabilização da invisibilidade (que também chamei de condição obscura). Anteriormente havia processos que tentavam dar visibilidade àqueles que estavam na penumbra da "ilegalidade", sempre mediados por noções gradualistas de semelhança. A última legislação apresentou-se como uma radicalização do princípio de assemelhamento, negando políticas amplas de visibilização e permitindo apenas que se tornem legais aqueles que provaram ser "assemelhados".

As formas de visibilização foram examinadas a partir da lógica da co-substancialidade, indicando como e quando algum estrangeiro é considerado "assemelhado". Vimos que há caminhos institucionais (escola, forças armadas), caminhos substantivos (casamento e filhos) e, por fim, caminhos temporais (permanência prolongada). Todo esse aparato legislativo indica determinadas concepções tanto de portuguesidade como de alteridade compartilhadas pelos legisladores, em alguma medida. O mais relevante é constatar que o processo de estabilização da invisibilidade dos imigrantes em "situação irregular" resulta de uma aversão à aceitação da diferença, levando à construção de todo um sistema legal de atribuição de direitos com base em uma noção bastante protegida de uma portuguesidade inefável.

\section{Referências bibliográficas}

Alexandre, Valentim (2000), "O império e a ideia de raça (séculos XIX e XX)", in Jorge Vala (coord.), Novos racismos. Perspectivas comparativas. Oeiras: Celta, 133-144. Baganha, Maria Ioannis (2001), "A cada Sul o seu Norte: dinâmicas migratórias em Portugal”, in Boaventura de Sousa Santos (org.), Globalização: Fatalidade ou Utopia? Porto: Afrontamento, 135-159.

Baganha, Maria Ioannis; Góis, Pedro (1998/1999), "Migrações internacionais de e para Portugal: o que sabemos e para onde vamos?”, Revista Crítica de Ciências Sociais, 52/53, 229-280.

Caetano da Silva, Eduardo (2003), Visões da diáspora portuguesa: dinâmicas identitárias e dilemas politicos entre os portugueses e luso-descendentes de São Paulo. Dissertação de mestrado. Campinas: Unicamp.

Canotilho, Joaquim Gomes (coord.) (2000), Direitos humanos, estrangeiros, comunidades migrantes e minorias. Oeiras: Celta Editora.

Carsten, Janet (2004), After Kinship. Cambridge: Cambridge University Press.

Castelo, Cláudia (1998), O modo português de estar no mundo. O luso-tropicalismo e a ideologia colonial portuguesa (1933-1961). Porto: Edições Afrontamento. 
Costa, Paulo Manuel (2006), “A legislação de estrangeiros em Portugal: a situação dos brasileiros”, in Igor José de Renó Machado (org.), Um mar de identidades: imigração brasileira em Portugal. São Carlos: Edufscar, 81-103.

Feldman-Bianco, Bela (2001), "Brazilians in Portugal, Portuguese in Brazil: Constructions of sameness and difference”, Identities: Global Studies in Culture and Power, 8(4), 607-650.

Fidalgo de Freitas, Tiago (2009), "Portuguese Migration Law - A Constitutional and Administrative Overview”, European Review of Public Law, 21(I), 345-401.

Jerónimo, Patrícia (2001), "Os direitos das minorias no ordenamento jurídico português: breve incursão pelos meandros do multiculturalismo”, Scientia Iuridica, 290, 69-81.

Machado, Igor José de Renó (2000), "Exclusão anunciada: reflexões sobre a nova lei de imigração portuguesa”, Revista Temáticas, 15/16, 67-72.

Machado, Igor José de Renó (2004), "Imigrantes brasileiros no Porto. Aproximação à perenidade de ordens raciais e coloniais portuguesas", Lusotopie, 1, 121-142.

Machado, Igor José de Renó (2005), "Implicações da imigração estimulada por redes ilegais de aliciamento: o caso dos brasileiros em Portugal”, Ilha Revista de Antropologia, 7, 187-212.

Machado, Igor José de Renó (2009), Cárcere público: processos de exotização entre imigrantes brasileiros no Porto. Lisboa: Editora do ICS.

Machado, Igor José de Renó (2010), “O manejo da diferença: reflexões sobre as políticas de imigração e controle de estrangeiros em Portugal e Brasil”, texto apresentado ao IV Fórum Mundial das Migrações, Quito, Equador (novembro).

Moura Ramos, Rui Manuel (1996), "Cidadania”, in Da Comunidade Internacional e do seu Direito. Coimbra: Coimbra Editora, 109-116.

Moura Ramos, Rui Manuel (2003), "Nacionalidade, plurinacionalidade e supranacionalidade na União Europeia e na Comunidade dos Países de Língua Portuguesa”, Boletim da Faculdade de Direito da Universidade de Coimbra, Coimbra, Vol. Comemorativo - 75 anos, 691-715.

Padilla, Beatriz (2007), “Acordos bilaterais e legalização: o impacte na integração dos imigrantes brasileiros em Portugal”, in Jorge Malheiros (org.), Imigração brasileira em Portugal. Lisboa: ACIDI.

Padilla, Beatriz (2005), "Integration of Brazilian Immigrants in Portuguese Society: Problems and possibilities", comunicação apresentada no Workshop Migrações Transatlânticas e Transeuropeias, em 18 de março, ISCTE, Lisboa.

Pereira da Silva, Jorge Manuel (2004), Direitos de cidadania e direito à cidadania. Lisboa: Observatório da Imigração.

Riquito, Ana Luísa (2000), "The Public/Private Dichotomy in International Refugee Law”, Boletim da Faculdade de Direito, Coimbra, vol. 76, 375-412.

Torres, Mário (1993), “A Lei dos Estrangeiros face à Constituição”, O Cidadão-Revista Trimestral de Direitos Humanos, ano I, n. ${ }^{\circ}$ 2, 27-34. 
Políticas de imigração e controle de estrangeiros em Portugal | 145

Urbano de Sousa, Maria Constança Dias (2000), "La régularisation d'étrangers illégaux au Portugal”, in P. De Bruycher (org.) Les régularisations d'étrangers illégaux dans l'Union Européenne/Regularisations of illegal immigrants in the European Union. Bruxelas: Ed. Bruylant.

Urbano de Sousa, Maria Constança Dias (2002), “The New Portuguese Immigration Act", European Journal of Migration and Law, 4/1, 49-69. 